\title{
Association among pre-pregnancy body mass index, gestational weight gain and neonatal birth weight: a prospective cohort study in China
}

Yawen Wang ${ }^{1,2}$ BD, Haihui Ma ${ }^{3}$, Yahui Feng ${ }^{1}$, Yongle Zhan ${ }^{1}$, Sansan $\mathrm{Wu}^{1}$, Shuya Cai ${ }^{1}$, Yingjie Shi', Yunli Chen ${ }^{1}$, Liangkun $\mathrm{Ma}^{4^{*}}$ and $\mathrm{Yu}$ Jiang ${ }^{1 *}$

\begin{abstract}
Background: This study aims to explore the relationships between pre-pregnancy body mass index (BMI), gestational weight gain (GWG), rate of GWG during the second and third trimesters (GWG $G_{\text {rate }}$ ) and birth weight among Chinese women.

Methods: Women were enrolled by 24 hospitals in 15 different provinces in mainland China from July 25th, 2017 to 26 November 2018. Pre-pregnancy BMI, GWG and GWG rate were calculated and divided in to different groups. The multinomial logistic regression model and restrictive cubic spline model were used to explore the relationships.

Results: Of the 3585 participants, women who were underweight, had insufficient GWG or GWG rate had 1.853-, 1850- or 1.524-fold higher risks for delivering small-for-gestational-age (SGA) infant compared with women who had normal BMI, sufficient GWG or GWG rate. Women who were overweight/obese, had excessive GWG or GWG rate had 1.996-, 1676- or 1.673-fold higher risks for delivering large-for-gestational-age (LGA) infant. The effects of GWG and GWG rate on birth weight varied by pre-pregnancy BMI statuses. Dose-response analysis demonstrated L-shaped and S-shaped relationships between pre-pregnancy BMI, GWG, GWG $\mathrm{G}_{\text {rate }}$ and neonatal birth weight.
\end{abstract}

Conclusions: Pre-pregnancy BMI, GWG or GWG rate were associated with neonatal birth weight among Chinese women. Both body weight before and during pregnancy should be maintained within the recommendations to prevent abnormal birth weight.

Keywords: Body mass index, Gestational weight gain, Small for gestational age, Large for gestational age

\footnotetext{
* Correspondence: maliangkun@pumch.cn; jiangyu@pumc.edu.cn

${ }^{4}$ Department of Obstetrics, Peking Union Medical College Hospital, Chinese

Academy of Medical Sciences/Peking Union Medical College, No.1,

Shuaifuyuan Wangfujing Dongcheng District, Beijing 100730, China

${ }^{1}$ School of Population Medicine and Public Health, Chinese Academy of

Medical Sciences/Peking Union Medical College, Beijing 100730, China

Full list of author information is available at the end of the article
}

C C The Author(s). 2020 Open Access This article is licensed under a Creative Commons Attribution 4.0 International License, which permits use, sharing, adaptation, distribution and reproduction in any medium or format, as long as you give appropriate credit to the original author(s) and the source, provide a link to the Creative Commons licence, and indicate if changes were made. The images or other third party material in this article are included in the article's Creative Commons licence, unless indicated otherwise in a credit line to the material. If material is not included in the article's Creative Commons licence and your intended use is not permitted by statutory regulation or exceeds the permitted use, you will need to obtain permission directly from the copyright holder. To view a copy of this licence, visit http://creativecommons.org/licenses/by/4.0/. The Creative Commons Public Domain Dedication waiver (http://creativecommons.org/publicdomain/zero/1.0/) applies to the data made available in this article, unless otherwise stated in a credit line to the data. 


\section{Background}

Since the 1980s, the overweight and obesity rates have doubled during the past four decades in more than 70 countries worldwide, and the rates are still increasing [1]. The same trend have been observed among Chinese adults: the overweight and obesity rates among this population were 20 and $7.1 \%$, respectively, according to a national survey conducted in 2002 [2]. For women of childbearing age, pre-pregnancy body mass index (BMI) is regarded as an important predictor of pregnancy outcomes since abnormal BMI has been verified to be related to a series of adverse maternal and neonatal complications [3-5]. However, the incidence of prepregnancy overweight and obesity has increased significantly around the world and has become an urgent public health problem. Gestational weight gain (GWG) is another factor that impacts fetal development, and insufficient or excessive GWG mostly results in restricted or over development. Asian women have been shown to have the highest prevalence of insufficient GWG (USA $21 \%$, Europe $18 \%$ and Asia 31\%), while more than half of American women have excessive GWG (USA 51\%, Europe 51\% and Asia 31\%) [6].

Although GWG is commonly used to evaluate fetal development, it has some limitations. Weight gain has different effects on fetal development in different trimesters, and total GWG failed to show trimester-specific weight change during pregnancy. A large number of clinical studies have demonstrated that women's weight gain during the 2nd and 3rd trimester $\left(\mathrm{GWG}_{\text {rate }}\right)$, which is also the period of maximal growth and weight gain for fetuses, is significantly associated with newborn weight while weight gain in the 1st trimester mostly affects overweight or obesity risk in the offspring's childhood [7]. Thus, $\mathrm{GWG}_{\text {rate }}$ is preferable for exploring the relationship between trimester-specific weight change and infant birth weight even though the data collection is complicated. The overall prevalence of insufficient and excessive $\mathrm{GWG}_{\text {rate }}$ varies in different regions $[8,9]$. Some studies showed that 12.5 and $57.9 \%$ of Chinese women had insufficient and excessive $\mathrm{GWG}_{\text {rate }}$ respectively in 2013 [10], but the updated incidence rate is unclear.

Most studies have shown that pre-pregnancy underweight and insufficient GWG are associated with a higher risk of having small for gestational age (SGA) infants but a lower risk of delivering large for gestational age (LGA) infants [11]. Similarly, pre-pregnancy overweight/obese and excessive GWG are associated with higher LGA risk but lower SGA risk despite of few studies that have inconsistent results [12-14]. However, some research indicates that the relationship between pre-pregnancy BMI, GWG and infant birth weight varies among different races of women, and whether the relationship is the same among Chinese women is not clear [15]. In addition, most research in China is province-based or city-based and lacks representativeness. As for the association between $\mathrm{GWG}_{\text {rate }}$ and birth weight, relevant studies are even mere, and the results are also inconsistent $[8,16]$. Furthermore, few studies have explored the dose-response relationship between women's body weight before or during pregnancy and infant birth weight. Hence, conducting more related studies and making the results more comprehensive is meaningful.

This study aimed to evaluate the prevalence of prepregnancy BMI, GWG and GWG rate in the 2nd and 3rd trimester, and to explore their associations with abnormal neonatal birth weight (i.e. SGA and LGA) among Chinese women, as well as the dose-response relationship between women's weight status before or during pregnancy and abnormal birth weight risks.

\section{Methods \\ Study setting and study population}

The Chinese Pregnant Women Cohort Study (CPWCS) is a multicenter, prospective cohort study focusing on antenatal women and their neonates. Twenty-four hospitals [see Table S1 in Additional file] distributed in 15 provinces in China were selected as the center sites through the comprehensive consideration of geography and economy. Pregnant women visiting anyone of 24 cooperated hospitals for their first trimester antenatal clinic with a gestational age of 5-13 weeks were enrolled. The study period of this cohort study was from 25 July 2017 to 26 November 2018 and the inclusion criteria were as follows: (1) 16 years old or above; (2) gestational age at 5-13 weeks (during the first trimester); (3) able to complete the questionnaires; (4) permanent residents (dwell in the local site for over 6 months) in the study locations; and (5) willing to sign the written informed consent form. In addition, women enrolled in this study must had single live birth after 28 gestational weeks. Other exclusion criteria included: less than 16 years of age; temporary residence; serious chronic diseases; psychosis; twin or multiple pregnancies; non-single live birth; and less than 28 gestational weeks.

\section{Data collection \\ Original data}

Participants were required to complete an electronic self-designed questionnaire in their first trimester and were followed up three times: in the second trimester, in the third trimester, and 42 days postpartum. Information provided by respondents includes basic sociodemographic characteristics, lifestyle behaviors, complications in each trimester and pregnancy outcomes. The prepregnancy weight and height of each respondent were 
self-reported when women were enrolled in this study, and pre-pregnancy BMI was assessed. Body weight at the beginning of the second trimester and at delivery were also collected, and the weight difference was GWG. Some important variables, such as pre-pregnancy body weight and weight at delivery, height, pregnancy complications, gestational age and pregnancy outcome were also checked with data recorded in the hospital information system (HIS) to maintain data quality.

\section{Classification of pre-pregnancy BMI, GWG and GWG rate} Pre-pregnancy BMI (weight $(\mathrm{kg}) /$ height $(\mathrm{m})^{2}$ ) was calculated by respondent's height and pre-pregnancy weight and was categorized into four groups according to standard WHO criteria: underweight (BMI $<18.5 \mathrm{~kg} /$ $\left.\mathrm{m}^{2}\right)$, normal-weight $\left(18.5 \mathrm{~kg} / \mathrm{m}^{2} \leq \mathrm{BMI} \leq 24.9 \mathrm{~kg} / \mathrm{m}^{2}\right)$, overweight $\left(25.0 \mathrm{~kg} / \mathrm{m}^{2} \leq \mathrm{BMI} \leq 29.9 \mathrm{~kg} / \mathrm{m}^{2}\right)$ and obese $\left(\mathrm{BMI} \geq 30.0 \mathrm{~kg} / \mathrm{m}^{2}\right)$ [17].

GWG was defined as the difference in weight at delivery and weight before pregnancy. According to the IOM recommendation, for pre-pregnancy underweight, normal weight, overweight and obese women, the appropriate GWGs are $12.5-18 \mathrm{~kg}, 11.5-16 \mathrm{~kg}, 7-11.5 \mathrm{~kg}$ and 5$9 \mathrm{~kg}$, respectively. Women with GWG below the recommended range were defined as having insufficient GWG, and those with GWG above the appropriate range were defined as having excessive GWG [18].

$\mathrm{GWG}_{\text {rate }}$ was calculated as (the difference of weight at delivery and weight at the beginning of 2nd trimester)/ (gestational age at delivery-13), whereas 13 was the cutoff value of the 1st and 2nd trimesters. According to IOM, for pre-pregnancy underweight, normal weight, overweight and obese women, the appropriate $\mathrm{GWG}_{\text {rate }}$ ranges are $0.44-0.58 \mathrm{~kg} / \mathrm{w}, 0.35-0.50 \mathrm{~kg} / \mathrm{w}, 0.23-0.33 \mathrm{~kg} /$ $\mathrm{w}$ and $0.17-0.27 \mathrm{~kg} / \mathrm{w}$, respectively [18]. Women with a $\mathrm{GWG}_{\text {rate }}$ below the recommended range were defined as having insufficient $G_{W} G_{\text {rate }}$, and those with $G_{W} G_{\text {rate }}$ above the appropriate range were defined as having excessive $\mathrm{GWG}_{\text {rate }}$.

\section{Definition of neonatal birth weight}

The main outcomes of this study were SGA and LGA. Birth weights below the 10th or above the 90th percentile, respectively, for the same gestational age by sex were defined as SGA and LGA according to the Chinese neonatal birth weight curve [19].

\section{Covariate assessments}

In this study, covariates included sociodemographic characteristics (i.e., maternal age, ethnicity, residential areas, educational level, occupation and annual household income), lifestyle behaviors (i.e., smoking and alcohol consumption), and clinical characteristics (gravidity, parity, gestational diabetes mellitus (GDM) and gestational hypertension). Gestational age was calculated as the difference in date from the last menstrual period to delivery. Alcohol consumption was defined as consuming any alcoholic beverage more than once per month. GDM was defined as meeting one or more of the following criteria: fasting plasma glucose $\geq 5.1 \mathrm{mmol} /$ $\mathrm{L}, 1 \mathrm{~h}$ plasma glucose levels $\geq 10.0 \mathrm{mmol} / \mathrm{L}, 2 \mathrm{~h}$ plasma glucose levels $\geq 8.5 \mathrm{mmol} / \mathrm{L}$ after overnight fasting with a $75 \mathrm{~g}$ glucose load at $24-28$ gestational weeks according to the diagnostic criteria amended by WHO in 2013 [20].

\section{Statistical analysis}

Qualitative variables were described as the mean values and standard deviations while quantitative variables were described as frequencies and percentages. The chisquare test and Kruskal-Wallis test were used for univariable analyses. Multinomial logistic regression models were conducted to explore the relationship between prepregnancy BMI, GWG, GWG $G_{\text {rare }}$, and birth weight and the results are shown as odds ratios (ORs) and 95\% confidence intervals (CIs). Dose-response relationships were explored by restricted cubic spline (RCS) logistic regression models. Three knots were located at the 25th, 50th and 75th percentiles of the distribution of each continuous dependent variable. RCS analysis was conducted by SAS 9.4 software with the RCS_Reg macro. All $P$ values in this study were two-sided and $P<0.05$ was regarded as a significant difference.

\section{Results}

A total of 3585 women were enrolled and maternal characteristics presented by neonatal birth weight are shown in Table 1. The overall prevalence of SGA and LGA was 5.77 and $10.54 \%$, respectively, among these respondents, and the average birth weight was $3321 \mathrm{~g}$ (SD: $453 \mathrm{~g}$ ). Women who were younger and employed were more likely to have SGA infants, while older and unemployed women tended to have LGA infants $(P<0.05)$. SGA mothers were shown to have fewer gravidities and parities than LGA mothers. In addition, women who gave birth to SGA infants were less likely to have GDM but had higher risk of gestational hypertension compared with women in the LGA group (all $P<0.05$ ).

Table S2 to Table S4 [see Additional file] show the demographic and clinical characteristics of the study participants by pre-pregnancy BMI, GWG and GWG $_{\text {rate }}$ categories. The prevalence of underweight, overweight and obesity before pregnancy was $14.17,12.86$ and $1.73 \%$, respectively. According to the IOM recommendation, 24.69 and $33.78 \%$ of women had insufficient and excessive GWG, respectively. Table S4 [see Additional file] illustrates the prevalence of SGA and LAG by pre-pregnancy, GWG and $\mathrm{GWG}_{\text {rate }}$ categories. Approximately $26.86 \%$ of 
Table 1 Maternal characteristics presented by neonatal birth weight [ $n(\%)]$

\begin{tabular}{|c|c|c|c|c|c|c|}
\hline Items & $\begin{array}{l}\text { Total } \\
N=3585\end{array}$ & $\begin{array}{l}\text { SGA } \\
N=207\end{array}$ & $\begin{array}{l}\text { AGA } \\
N=3000\end{array}$ & $\begin{array}{l}\text { LGA } \\
N=378\end{array}$ & $X^{2} / H$ & $P$ \\
\hline \multicolumn{5}{|l|}{ Age } & 3.004 & 0.048 \\
\hline$<25$ & $576(16.07)$ & $37(17.87)$ & $482(16.07)$ & $57(15.08)$ & & \\
\hline $25 \sim$ & $1804(50.32)$ & $113(54.59)$ & $1516(50.53)$ & $175(46.30)$ & & \\
\hline $30 \sim$ & $859(23.96)$ & $39(18.84)$ & $721(24.03)$ & 99 (26.19) & & \\
\hline $35 \sim$ & $346(9.65)$ & $18(8.70)$ & $281(9.37)$ & $47(12.43)$ & & \\
\hline \multicolumn{5}{|l|}{ Ethnicity } & 3.044 & 0.218 \\
\hline Han & $3413(95.20)$ & $192(92.75)$ & $2859(95.30)$ & $362(95.77)$ & & \\
\hline Minority & $172(4.80)$ & $15(7.25)$ & $141(4.70)$ & $16(4.23)$ & & \\
\hline \multicolumn{5}{|l|}{ Residential Areas } & 0.425 & 0.809 \\
\hline Urban & $1594(44.46)$ & $90(43.48)$ & $1341(44.70)$ & $163(43.12)$ & & \\
\hline Rural & $1991(55.37)$ & 117 (56.52) & $1659(55.30)$ & 215 (56.88) & & \\
\hline \multicolumn{5}{|l|}{ Educational level } & 10.422 & 0.108 \\
\hline Less than high school & $508(14.17)$ & $21(10.15)$ & $418(13.93)$ & $69(18.26)$ & & \\
\hline High school & $765(21.34)$ & $42(20.29)$ & $648(21.60)$ & $75(19.84)$ & & \\
\hline Bachelor & $2082(58.07)$ & $133(64.25)$ & $1735(57.84)$ & $214(56.61)$ & & \\
\hline Master or above & $230(6.42)$ & $11(5.31)$ & $199(6.63)$ & $20(5.29)$ & & \\
\hline \multicolumn{5}{|l|}{ Occupation } & 14.378 & 0.026 \\
\hline No & $1064(29.68)$ & $42(20.29)$ & $908(30.27)$ & $114(30.16)$ & & \\
\hline Yes & $2521(70.32)$ & $165(79.71)$ & $2092(69.73)$ & $264(69.84)$ & & \\
\hline \multicolumn{5}{|c|}{ Annual household Income (thousand) } & 3.628 & 0.459 \\
\hline$<70$ & $959(26.75)$ & $44(21.26)$ & $816(27.20)$ & $99(26.19)$ & & \\
\hline $70 \sim$ & $1656(46.19)$ & $104(50.24)$ & $1375(45.83)$ & $177(46.83)$ & & \\
\hline $200 \sim$ & $970(27.06)$ & $59(28.50)$ & $809(26.97)$ & $102(26.98)$ & & \\
\hline \multicolumn{5}{|l|}{ Smoking } & 0.881 & 0.644 \\
\hline No & $3424(95.51)$ & $195(94.20)$ & $2868(95.60)$ & $361(95.50)$ & & \\
\hline Yes & $161(4.49)$ & $12(5.80)$ & $132(4.40)$ & $17(4.50)$ & & \\
\hline \multicolumn{5}{|l|}{ Alcohol consumption } & 0.718 & 0.698 \\
\hline No & $3325(92.75)$ & $189(91.30)$ & $2786(92.87)$ & $350(92.60)$ & & \\
\hline Yes & $260(7.25)$ & $18(8.70)$ & $214(7.13)$ & $28(7.40)$ & & \\
\hline \multicolumn{5}{|l|}{ Gravidity } & 30.204 & $<0.001$ \\
\hline 0 & $1085(30.27)$ & $96(46.38)$ & $883(29.43)$ & $106(28.04)$ & & \\
\hline 1 & $1192(33.25)$ & $53(25.60)$ & $1020(34.00)$ & $119(31.48)$ & & \\
\hline 2 & $755(21.06)$ & $35(16.91)$ & $627(20.90)$ & $93(24.60)$ & & \\
\hline$\geq 3$ & $553(15.42)$ & $23(11.11)$ & $470(15.67)$ & $60(15.88)$ & & \\
\hline \multicolumn{5}{|l|}{ Parity } & 8.236 & 0.021 \\
\hline 0 & $2080(58.02)$ & $136(65.70)$ & $1733(57.77)$ & $211(55.82)$ & & \\
\hline 1 & $1292(36.04)$ & $63(30.44)$ & $1085(36.17)$ & $144(38.10)$ & & \\
\hline 2 & $145(4.05)$ & $4(1.93)$ & $123(4.10)$ & $18(4.76)$ & & \\
\hline$\geq 3$ & $68(1.89)$ & $4(1.93)$ & $59(1.96)$ & $5(1.32)$ & & \\
\hline \multicolumn{5}{|l|}{ GMD } & 6.122 & 0.047 \\
\hline No & $3089(86.17)$ & $179(86.47)$ & $2600(86.67)$ & $310(82.01)$ & & \\
\hline Yes & $496(13.83)$ & $28(13.53)$ & $400(13.33)$ & $68(17.99)$ & & \\
\hline \multicolumn{5}{|l|}{ Gestational Hypertension } & 8.611 & 0.013 \\
\hline No & $3475(96.93)$ & 194 (93.72) & $2917(97.23)$ & 364 (96.30) & & \\
\hline Yes & $110(3.07)$ & $13(6.28)$ & $83(2.77)$ & $14(3.70)$ & & \\
\hline Gestational Week & $39.23 \pm 1.44$ & $39.15 \pm 1.54$ & $39.24 \pm 1.43$ & $39.13 \pm 1.50$ & 3.018 & 0.221 \\
\hline
\end{tabular}


women showed insufficient GWG $_{\text {rate }}$ while $46.95 \%$ had excessive $\mathrm{GWG}_{\text {rate }}$. The average birth weight of infants was associated with women's pre-pregnancy BMI, GWG and $\mathrm{GWG}_{\text {rate }}(P<0.001)$.

The multinomial logistic regression analysis results are shown in Table 2. Women who were underweight before pregnancy, had insufficient GWG or had insufficient $\mathrm{GWG}_{\text {rate }}$ were 1.9-,1,9- and 1.5-fold more likely to have SGA infants, respectively, compared with reference groups, and women who were overweight or obese before pregnancy, had excessive GWG or had excessive $\mathrm{GWG}_{\text {rate }}$ were 2.0-,1.7- and 1.7-fold more likely to have LGA infants, respectively. Additionally, protective effects were shown between excessive $\mathrm{GWG}_{\text {rate }}$ and SGA, as well as pre-pregnancy underweight, insufficient GWG and LGA.

Chi-square analysis demonstrated the relationship between birth weight and jointed pre-pregnancy BMI and GWG/GWG rate [see Table S5 to Table S7 in Additional file]. The prevalence of insufficient GWG in the prepregnancy underweight, normal weight and overweight/ obesity groups was $28.54,27.21$ and $8.60 \%$, respectively, and the prevalence of excessive GWG was 24.41, 30.58 and $58.51 \%$, respectively, in each group. GWG and $\mathrm{GWG}_{\text {rate }}$ were associated with infant birth weight under different pre-pregnancy BMI levels $(P<0.05)$.

Stratified analysis results are shown in Table 3. Among the pre-pregnancy underweight, normal weight and overweight/obese groups, women with insufficient GWG were 3.0-, 1.2- and 6.7-fold more likely to have SGA infants, respectively. Excessive GWG among normal weight and overweight/obese women was 1.6- and 2.3-

Table 2 Adjusted OR for birth weight classified by prepregnancy BMI, GWG and GWG rate

\begin{tabular}{|c|c|c|c|c|}
\hline \multirow[t]{2}{*}{ Items } & \multicolumn{2}{|l|}{ SGA } & \multicolumn{2}{|l|}{ LGA } \\
\hline & $\overline{\mathrm{OR}}$ & $95 \% \mathrm{Cl}$ & $\overline{\mathrm{OR}}$ & $95 \% \mathrm{Cl}$ \\
\hline \multicolumn{5}{|l|}{ Pre-BMI $^{\text {a }}$} \\
\hline Underweight & $1.853^{c}$ & $1.316-2.610$ & $0.575^{d}$ & $0.383-0.864$ \\
\hline Normal weight & Ref. & & Ref. & \\
\hline Overweight/Obesity & 0.576 & $0.328-1.010$ & $1.996^{c}$ & $1.540-2.588$ \\
\hline \multicolumn{5}{|l|}{ GWG b } \\
\hline Insufficient & $1.850^{c}$ & $1.309-2.616$ & $0.601^{d}$ & $0.399-0.903$ \\
\hline adequate & Ref. & & Ref. & \\
\hline Excessive & 0.628 & $0.351-1.125$ & $1.676^{c}$ & $1.279-2.194$ \\
\hline \multicolumn{5}{|l|}{$G W G_{\text {rate }} b$} \\
\hline Insufficient & $1.524^{d}$ & $1.068-2.174$ & 0.846 & $0.600-1.193$ \\
\hline adequate & Ref. & & Ref. & \\
\hline Excessive & $0.668^{d}$ & $0.458-0.973$ & $1.673^{c}$ & $1.274-2.196$ \\
\hline
\end{tabular}

${ }^{a}$ Adjusted for maternal age, occupation, gravidity, parity; ${ }^{\mathrm{b}}$ Adjusted for maternal age, occupation, gravidity, parity, GDM, gestational hypertension and pre-BMl; ${ }^{c} P<0.001 ;{ }^{d} P<0.05$ fold more likely to have LGA infants, respectively. Only excessive GWG among the normal weight group had a protective effect on SGA.

The association of neonatal birth weight with $\mathrm{GWG}_{\text {rate }}$ under each pre-pregnancy BMI level is shown in Table 4. For women with normal BMI before pregnancy, excessive $\mathrm{GWG}_{\text {rate }}$ was associated with a 1.6 times higher risk for LGA but a 0.35 times lower risk for SGA. Excessive $\mathrm{GWG}_{\text {rate }}$ also contributed to a 1.7 times higher risk for LGA among pre-pregnancy overweight and obese women, and insufficient $\mathrm{GWG}_{\text {rate }}$ was associated with a 0.81 times lower LGA risk in this group.

Figure 1 shows dose-response relationships between neonatal birth weight and women's body weight before and during pregnancy. The RCS logistic regression models showed that except for the nonlinear association between $\mathrm{GWG}_{\text {rate }}$ and LGA $\left(\mathrm{P}_{\text {nonlinear }}<0.001\right)$, the other associations were linear $\left(\mathrm{P}_{\text {nonlinear }}>0.05\right)$.

\section{Discussion}

In this study, we found that pre-pregnancy underweight and insufficient GWG were associated with higher SGA risk and lower LGA risk while pre-pregnancy overweight or obese and excessive GWG were associated with higher LGA risk and lower SGA risk. GWG $\mathrm{Gate}_{\text {was also }}$ associated with neonatal birthweight. The association of GWG and $\mathrm{GWG}_{\text {rate }}$ with birth weight varies with prepregnancy BMI status. Dose-response relationships existed between pre-pregnancy BMI, GWG, GWG rate and newborn weight.

The relationships this study found between prepregnancy BMI, GWG and GWG rate are consistent with the findings of some existing studies [21-23], including a cohort study located in three provinces in southwest China [24]. A meta-analysis showed that insufficient GWG contributed to a lower risk for LGA while excessive GWG was associated with lower risk for SGA [11]. We also found that insufficient GWG was associated with lower LGA, but this relationship disappeared when we adjusted pre-pregnancy BMI. Xie [25] found that excessive GWG increased neonatal birth weight, but no relationship was found between pre-pregnancy BMI and birth weight. However, Ratnasiri [26] conducted a retrospective cohort study, and the results showed prepregnancy overweight and obese contributed to a lower SGA rate and pre-pregnancy underweight decreased the risk of LGA. These differences may be attributed to ethnicity. As for $\mathrm{GWG}_{\text {rate }}$, another Chinese cohort study indicated that excessive $\mathrm{GWG}_{\text {rate }}$ increased LGA risk, but insufficient $\mathrm{GWG}_{\text {rate }}$ had no impact on SGA, and this result was inconsistent with our finding [27]. Differences in findings may be due to different study population since this study was conducted in 15 different provinces and the sample could better represent Chinese women. 
Table 3 Adjusted OR for birth weight classified by jointed pre-pregnancy BMI and GWG

\begin{tabular}{|c|c|c|c|c|c|}
\hline \multirow{2}{*}{$\begin{array}{l}\text { Pre-BMI/ } \\
\text { GWG }\end{array}$} & \multirow[t]{2}{*}{$N(\%)$} & \multicolumn{2}{|l|}{ SGA } & \multicolumn{2}{|l|}{ LGA } \\
\hline & & $\overline{O R}^{a}$ & $95 \% \mathrm{Cl}$ & $\overline{\mathrm{OR}^{\mathrm{a}}}$ & $95 \% \mathrm{Cl}$ \\
\hline \multicolumn{6}{|l|}{ Underweight } \\
\hline Insufficient & $145(4.04)$ & $2.961^{b}$ & $1.491-5.881$ & 0.576 & $0.176-1.884$ \\
\hline adequate & $239(6.67)$ & Ref. & & Ref. & \\
\hline Excessive & $124(3.46)$ & 0.886 & $0.354-2.217$ & 1.730 & $0.690-4.336$ \\
\hline \multicolumn{6}{|l|}{ Normal weight } \\
\hline Insufficient & 695 (19.39) & $1.236^{c}$ & $1.036-1.828$ & 0.988 & $0.699-1.397$ \\
\hline adequate & $1078(30.07)$ & Ref. & & Ref. & \\
\hline Excessive & 781 (21.79) & $0.614^{c}$ & $0.388-0.972$ & $1.623^{*}$ & $1.201-2.194$ \\
\hline \multicolumn{6}{|c|}{ Overweight/Obesity } \\
\hline Insufficient & $45(1.25)$ & $6.672^{c}$ & $1.386-32.118$ & 0.518 & $0.144-1.859$ \\
\hline adequate & $172(4.80)$ & Ref. & & Ref. & \\
\hline Excessive & $306(8.53)$ & 1.220 & $0.274-5.420$ & $2.287^{c}$ & $1.318-3.969$ \\
\hline
\end{tabular}

${ }^{\mathrm{a}}$ Adjusted for maternal age, occupation, gravidity, parity, GDM and gestational hypertension; ${ }^{\mathrm{b}} P<0.001 ;{ }^{\mathrm{c}} P<0.05$

The research mentioned above mostly focuses on specific areas of China or foreign countries, and various cultures, lifestyles, economic statuses and many other factors may contribute to the differences in the results.

The association of GWG and $\mathrm{GWG}_{\text {rate }}$ and birth weight varies with different pre-pregnancy BMI statuses. Stratified analysis showed that insufficient GWG increased SGA risk only in pre-pregnancy underweight or normal weight women, rather than overweight or obese women. This finding is consistent with a cohort study targeted at US women [28]. This study also found that excessive GWG decreased SGA risk only in women with a normal body weight before pregnancy. However, this finding is inconsistent with a retrospective cohort study conducted by $\mathrm{Li}$ [29], which showed that excessive
GWG had a protective effect on SGA in pre-pregnancy overweight and obese women. We also did not find that GWG made any effort towards LGA in pre-pregnancy underweight women. Excessive $\mathrm{GWG}_{\text {rate }}$ was associated with a higher risk of LGA except in pre-pregnancy underweight women, and it was found to decrease SGA risk only in pre-pregnancy normal weight. However, some research [30] found that insufficient $\mathrm{GWG}_{\text {rate }}$ could decrease LGA risk in pre-pregnancy underweight women, but we did not find the same results. This study also did not show relationship between insufficient $\mathrm{GWG}_{\text {rate }}$ and the risk of SGA, which are commonly believed to be associated. This difference indicates that more comprehensive and well-designed studies are needed to help determining consistent results.

Table 4 Adjusted OR for birth weight classified by jointed pre-pregnancy BMI and GWG

\begin{tabular}{|c|c|c|c|c|c|}
\hline \multirow{2}{*}{$\begin{array}{l}\text { Pre-BMI/ } \\
\text { GWG }_{\text {rate }}\end{array}$} & \multirow[t]{2}{*}{$N(\%)$} & \multicolumn{2}{|l|}{ SGA } & \multicolumn{2}{|l|}{ LGA } \\
\hline & & $\mathrm{OR}^{\mathrm{a}}$ & $95 \% \mathrm{Cl}$ & $\mathrm{OR}^{\mathrm{a}}$ & $95 \% \mathrm{Cl}$ \\
\hline \multicolumn{6}{|l|}{ Underweight } \\
\hline Insufficient & $205(5.72)$ & 1.760 & $0.799-3.874$ & 1.860 & $0.556-6.220$ \\
\hline adequate & $128(3.57)$ & Ref. & & Ref. & \\
\hline Excessive & $175(4.88)$ & 0.910 & $0.370-2.239$ & 3.305 & 0.990-11.038 \\
\hline \multicolumn{6}{|l|}{ Normal weight } \\
\hline Insufficient & $698(19.47)$ & 1.514 & $0.922-2.311$ & 0.962 & $0.648-1.430$ \\
\hline adequate & 683 (19.05) & Ref. & & Ref. & \\
\hline Excessive & $1173(32.72)$ & $0.650^{b}$ & $0.387-0.945$ & $1.606^{b}$ & $1.155-2.233$ \\
\hline \multicolumn{6}{|c|}{ Overweight/Obesity } \\
\hline Insufficient & $60(1.67)$ & 0.805 & $0.135-4.811$ & $0.190^{b}$ & $0.042-0.853$ \\
\hline adequate & $128(3.57)$ & Ref. & & Ref. & \\
\hline Excessive & $335(9.35)$ & 0.515 & $0.146-1.809$ & $1.698^{b}$ & $1.062-2.996$ \\
\hline
\end{tabular}

\footnotetext{
${ }^{\mathrm{a}}$ Adjusted for maternal age, occupation, gravidity, parity, GDM and gestational hypertension; ${ }^{\mathrm{b}} P<0.05$
} 
A

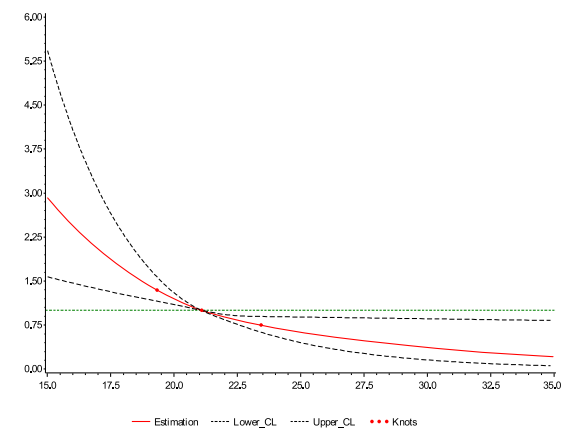

C

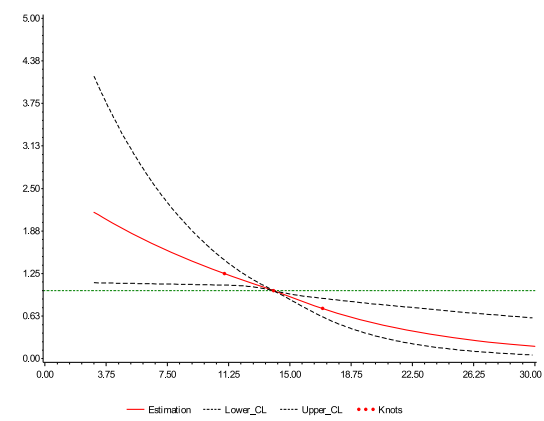

E

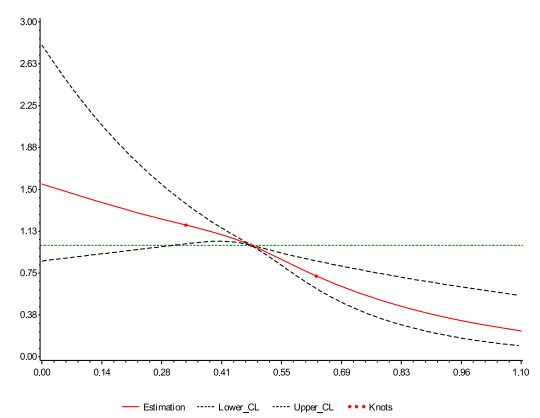

B

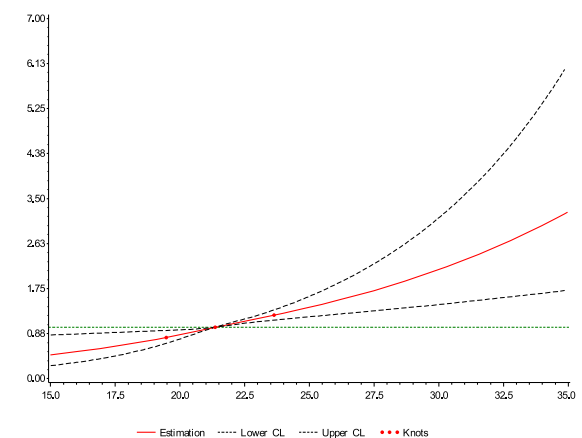

D

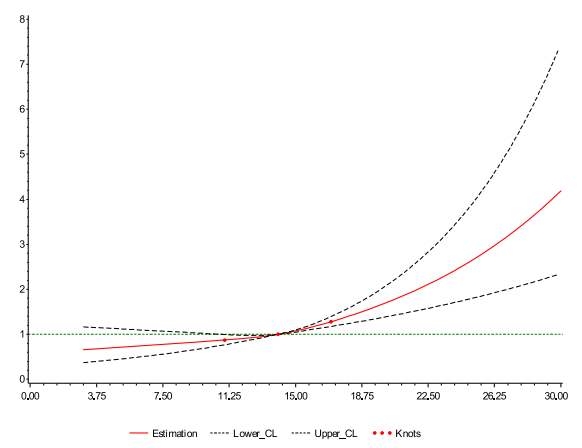

F

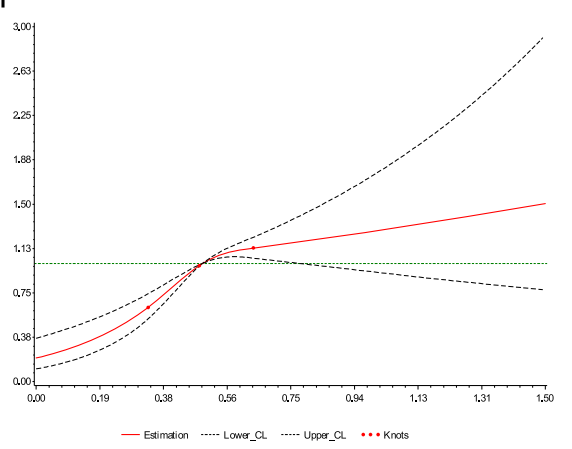

Fig. 1 Dose-response relationships. ORs and 95\%Cls for pre-pregnancy BMI (a,b), GWG (c,d) and GWG rate $_{\text {e }}(\mathbf{e}, \mathbf{f})$ with SGA $(\mathbf{a}, \mathbf{c}, \mathbf{e})$ and LGA (b,d,f). a and $\mathbf{b}$ adjusted for maternal age, occupation, gravidity and parity; $\mathbf{c}, \mathbf{d}, \mathbf{e}, \mathbf{f}$ also adjusted for pre-pregnancy BMI, GDM and gestational hypertension. The solid curve in each figure is OR value while two dash curves are $95 \%$ confidence intervals

There are relatively few studies focusing on the doseresponse relationship between women's body weight before and during pregnancy and infant birth weight. Consistent results can be found through these studies that a dose-response relationship exists, but the shapes of these curves are different [31, 32]. Except for the relationship between GWG $_{\text {rate }}$ and LGA, which showed an 'S-shaped' carve, others were 'L-shaped' in this study. These results were different from those of the previously mentioned studies, which may be attributed to different research populations or study designs. Nevertheless, doseresponse research on this topic is mere, and far more studies are needed.
The novelty of this study is significant. First, this study explored the protective effects of pre-pregnancy underweight/ insufficient GWG and GWG rate on LGA infants among Chinese women and the protective effects of prepregnancy overweight and obese/ excessive GWG and GWG $_{\text {rate }}$ on SGA infants, which are still inconsistent yet. Second, stratified analysis was adopted to explore the relationships between $\mathrm{GWG} / \mathrm{GWG}_{\text {rate }}$ and birth weight under different pre-pregnancy BMI levels, and this made our study more comprehensive and accurate; Third, this study analyzed $\mathrm{GWG}_{\text {rate }}$, which was less commonly researched due to cumbersome measurement, and the results can provide references for further 
relevant research. Fourth, we explored the doserelationships between women's body weight before and during pregnancy and neonatal birth weight, and this was focused by only few studies around the word.

This study has some strengths and limitations. This nationwide multicenter prospective cohort study enrolled people living in 15 different provinces in China, and this sample can well represent Chinese women. Core data, including weight before pregnancy and weight at delivery, gestational age and neonatal birth weight, were double checked to maintain data quality, which means data collected by questionnaire were checked with that recorded in the HIS system of each hospital. If there was any inconsistency, a medical record was preferred unless it was illogical. For limitations, respondents were asked to recall their pre-pregnancy body weight and height, which may result in recall bias. In addition, convenience sampling may decrease the representativeness of our results. We did not conduct subgroup analysis stratified by obesity class due to the small sample size of pre-pregnancy obese women. However, this subgroup analysis may provide more detailed references for body weight control before pregnancy and it should be explored in the future.

\section{Conclusions}

In summary, this study showed that pre-pregnancy underweight, insufficient GWG and GWG $_{\text {rate }}$ increased the risk of SGA while pre-pregnancy overweight or obese, excessive GWG and GWG rate increased the risk of LGA. In addition, these relationships varied according to different pre-pregnancy BMI statuses. Dose-response relationships were observed between independent and dependent variates mentioned above. Our results emphasized the significance of body weight control both before and during pregnancy. Although it may be difficult for women to adhere the IOM recommendation, interventions such as education should be imposed to help achieving suitable pre-pregnancy BMI and GWG [33].

\section{Supplementary information}

The online version contains supplementary material available at https://doi. org/10.1186/s12884-020-03323-x.

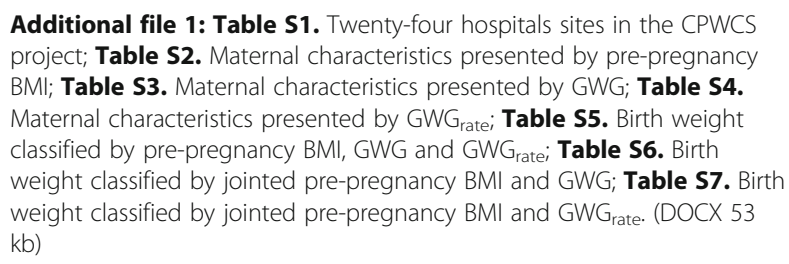

\section{Abbreviations}

BMl: Body mass index; GWG: Gestational weight gain; $\mathrm{GWG}_{\text {rate: }}$ : Rate of gestational weight gain during the second and third trimesters; SGA: Small for gestational age; LGA: Large for gestational age

\section{Acknowledgements}

We would like to express our gratitude to all 24 hospitals and investigators of CPWCS for their contributions in data collection. We thank all participants for sharing their time and experiences. We also thank anonymous peer reviewers for carefully revising our manuscript and for his or her useful comments.

\section{Authors' contributions}

YW: Conceptualization, Methodology, Formal analysis, Writing-Original draft preparation, Writing- Reviewing and Editing. HM: Methodology, Investigation, Data curation, Writing- Reviewing and Editing. YF, SW, YS and YC: Investigation, Validation. YZ and SC: Data curation, Methodology. LM: Supervision, Project administration. YJ: Conceptualization, Writing- Reviewing and Editing, Supervision, Project administration. All authors have read and approved the manuscript.

\section{Funding}

This study was founded by the CAMS Initiative for Innovative Medicine (2019-I2M-2-007). However, it had no role in study design, data collection, analysis and interpretation, as well as drafting the manuscript.

\section{Availability of data and materials}

The datasets used and/or analyzed during the current study are available from the corresponding author on reasonable request.

\section{Ethics approval and consent to participate}

This study has been approved by the Ethics Review Committee at Department of Scientific Research, Peking Union Medical College Hospital, Beijing, China (ID: HS-1345, May 23rd 2017). All study centers signed and authorized Peking Union Medical College Hospital, the leader of this study, to conduct ethic review and all centers recognized the results. Since no children (under 16 years old) was enrolled in this study, all participants provided informed consent with their own signature.

Consent for publication

Not applicable.

\section{Competing interests}

The authors declare that they have no competing interests.

\section{Author details}

'School of Population Medicine and Public Health, Chinese Academy of Medical Sciences/Peking Union Medical College, Beijing 100730, China. ${ }^{2}$ The Jockey Club School of Public Health and Primary Care, The Chinese University of Hong Kong, Hongkong, Hong Kong, China. ${ }^{3}$ Department of obstetrics, Tongzhou Mater\&Child health hospital of Beijing, Yuqiaozhong Road, Tongzhou District, Beijing 101100, China. ${ }^{4}$ Department of Obstetrics, Peking Union Medical College Hospital, Chinese Academy of Medical Sciences/Peking Union Medical College, No.1, Shuaifuyuan Wangfujing Dongcheng District, Beijing 100730, China.

Received: 6 April 2020 Accepted: 9 October 2020

Published online: 12 November 2020

\section{References}

1. Neeland IJ, Poirier P, Despres JP. Cardiovascular and metabolic heterogeneity of obesity: clinical challenges and implications for management. Circulation. 2018;137(13):1391-406.

2. Wu YF, Ma GS, Hu YH, Li YP, Li X, Cui ZH, Chen CM, Kong LZ. The current prevalence status of body overweight and obesity in China: data from the China National Nutrition and health survey. Zhonghua Yu Fang Yi Xue Za Zhi. 2005;39(5):316-20.

3. Zhang $D$, Zhang $L$, Wang $Z$. The relationship between maternal weight gain in pregnancy and newborn weight. Women Birth. 2019;32(3):270-5.

4. Pongcharoen T, Gowachirapant S, Wecharak P, Sangket N, Winichagoon P. Pre-pregnancy body mass index and gestational weight gain in Thai pregnant women as risks for low birth weight and macrosomia. Asia Pac J Clin Nutr. 2016;25(4):810-7.

5. Voerman E, Santos S, Inskip H, Amiano P, Barros H, Charles MA, Chatzi L, Chrousos GP, Corpeleijn E, Crozier S, et al. Association of Gestational Weight 
Gain with Adverse Maternal and Infant Outcomes. JAMA. 2019;321(17): 1702-15.

6. Goldstein RF, Abell SK, Ranasinha S, Misso ML, Boyle JA, Harrison CL, Black MH, Li N, Hu G, Corrado F, et al. Gestational weight gain across continents and ethnicity: systematic review and meta-analysis of maternal and infant outcomes in more than one million women. BMC Med. 2018:16(1):153.

7. Karachaliou M, Georgiou V, Roumeliotaki T, Chalkiadaki G, Daraki V, Koinaki S, Dermitzaki E, Sarri K, Vassilaki M, Kogevinas M, et al. Association of trimester-specific gestational weight gain with fetal growth, offspring obesity, and cardiometabolic traits in early childhood. Am J Obstet Gynecol. 2015;212(4):501-2.

8. Deierlein AL, Messito MJ, Katzow M, Berube LT, Dolin CD, Gross RS. Total and trimester-specific gestational weight gain and infant anthropometric outcomes at birth and 6 months in low-income Hispanic families. Pediatr Obes. 2020;15(3):e12589.

9. Drehmer M, Duncan BB, Kac G, Schmidt MI. Association of second and third trimester weight gain in pregnancy with maternal and fetal outcomes. PLoS One. 2013;8(1)::54704.

10. Huang A, Ji Z, Zhao W, Hu H, Yang Q, Chen D. Rate of gestational weight gain and preterm birth in relation to prepregnancy body mass indices and trimester: a follow-up study in China. Reprod Health. 2016;13(1):93.

11. Goldstein RF, Abell SK, Ranasinha S, Misso M, Boyle JA, Black MH, Li N, Hu G, Corrado F, Rode L, et al. Association of Gestational Weight Gain with Maternal and Infant Outcomes. JAMA. 2017;317(21):2207.

12. Mohammadi M, Maroufizadeh S, Omani-Samani R, Almasi-Hashiani A, Amini $P$. The effect of prepregnancy body mass index on birth weight, preterm birth, cesarean section, and preeclampsia in pregnant women. J Matern Fetal Neonatal Med. 2019;32(22):3818-23.

13. Heerman WJ, Bian A, Shintani A, Barkin SL. Interaction between maternal Prepregnancy body mass index and gestational weight gain shapes infant growth. Acad Pediatr. 2014;14(5):463-70.

14. Tabb KM, Malinga T, Pineros-Leano M, Andrade F. Impact of pre-pregnancy weight and gestational weight gain on birth outcomes by nativity in the United States: a systematic review. Healthcare (Basel). 2017;5(4):67.

15. Lin X, Aris IM, Tint MT, Soh SE, Godfrey KM, Yeo GS, Kwek K, Chan JK, Gluckman PD, Chong YS, et al. Ethnic differences in effects of maternal prepregnancy and pregnancy adiposity on offspring size and adiposity. J Clin Endocrinol Metab. 2015;100(10):3641-50

16. Sridhar SB, Xu F, Hedderson MM. Trimester-specific gestational weight gain and infant size for gestational age. PLoS One. 2016;11(7):e159500.

17. Hughes MM, Black RE, Katz J. 2500-g low birth weight cutoff: history and implications for future research and policy. Matern Child Health J. 2017; 21(2):283-9.

18. Committee IOMU, Guidelines RIPW. Weight Gain During Pregnancy: Reexamining the Guidelines. Washington (DC): National Academies Press (US); 2009.

19. Zhu L, Zhang R, Zhang S, Shi W, Yan W, Wang X, Lyu Q, Liu L, Zhou Q. Qiu $Q$ et al: [Chinese neonatal birth weight curve for different gestational age]. Zhonghua Er Ke Za Zhi. 2015;53(2):97-103.

20. Sun Y, Shen Z, Zhan Y, Wang Y, Ma S, Zhang S, Liu J, Wu S, Feng Y, Chen Y, et al. Effects of -pre-pregnancy body mass index and gestational weight gain on maternal and infant complications. BMC Pregnancy Childbirth. 2020;20:390

21. Zhao R, Xu L, Wu ML, Huang SH, Cao XJ. Maternal pre-pregnancy body mass index, gestational weight gain influence birth weight. Women Birth. 2018;31(1):e20-5.

22. Mastroeni MF, Czarnobay SA, Kroll C, Fiqueiredo KB, Mastroeni SS, Silva JC, Khan MK, Loehr S, Veugelers PJ. The independent importance of prepregnancy weight and gestational weight gain for the prevention of largefor gestational age Brazilian newborns. Matern Child Health J. 2017;21(4): 705-14.

23. Nowak M, Kalwa M, Oleksy P, Marszalek K, Radon-Pokracka M, Huras H. The relationship between pre-pregnancy BMI, gestational weight gain and neonatal birth weight: a retrospective cohort study. Ginekol Pol. 2019;90(1):50-4.

24. Li DT, Liang Y, Gong YH, Chen MX, Feng P, Yang DG, Yang WY, Liu Y. Cheng G: [relations between pregestational body mass index, gestational weight gain and birth weight of neonates among women in the southwest areas of China: a prospective cohort study]. Zhonghua Liu Xing Bing Xue Za Zhi. 2018;39(10):1319-23.

25. Xie YJ, Peng R, Han L, Zhou X, Xiong Z, Zhang Y, Li J, Yao R, Li T, Zhao Y. Associations of neonatal high birth weight with maternal pre-pregnancy body mass index and gestational weight gain: a case-control study in women from Chongqing, China. BMJ Open. 2016;6(8):e10935.

26. Ratnasiri A, Lee HC, Lakshminrusimha S, Parry SS, Arief VN, DeLacy $\mathbb{H}_{\text {, }}$ Yang JS, DiLibero RJ, Logan J, Basford KE. Trends in maternal prepregnancy body mass index (BMI) and its association with birth and maternal outcomes in California, 2007-2016: a retrospective cohort study. PLoS One. 2019;14(9): e222458.

27. Pugh SJ, Albert PS, Kim S, Grobman W, Hinkle SN, Newman RB, Wing DA, Grantz KL. Patterns of gestational weight gain and birthweight outcomes in the Eunice Kennedy Shriver National Institute of Child Health and Human Development fetal growth studies-singletons: a prospective study. Am J Obstet Gynecol. 2017;217(3):341-6.

28. Shin $\mathrm{D}$, Song WO. Prepregnancy body mass index is an independent risk factor for gestational hypertension, gestational diabetes, preterm labor, and small- and large-for-gestational-age infants. J Matern Fetal Neonatal Med. 2015;28(14):1679-86.

29. Li C, Liu Y, Zhang W. Joint and independent associations of gestational weight gain and pre-pregnancy body mass index with outcomes of pregnancy in Chinese women: a retrospective cohort study. PLoS One. 2015;10(8):e136850.

30. Wang $X$, Zhang $X$, Zhou M, Juan J, Wang X. Association of prepregnancy body mass index, rate of gestational weight gain with pregnancy outcomes in Chinese urban women. Nutr Metab. 2019;16(1):54.

31. Mao Y, Hu W, Liu Q, Li Y, Shen Y. A dose-response analysis on the association of gestational weight gain rate and the normal term neonate birth weight. Zhonghua Liu Xing Bing Xue Za Zhi. 2015;36(8):879-83.

32. Mao Y, Wang S, Li M, Huang M, Mo M, Gu L, Muyiduli X, Lian H, Jiang S, Wang $Z$, et al. Association of trimester-specific gestational weight gain with birth weight and fetal growth in a large community-based population. Arch Gynecol Obstet. 2019;300:313-22.

33. Rogozinska E, Zamora J, Marlin N, Betran AP, Astrup A, Bogaerts A, Cecatti JG, Dodd JM, Facchinetti F, Geiker N, et al. Gestational weight gain outside the Institute of Medicine recommendations and adverse pregnancy outcomes: analysis using individual participant data from randomised trials. BMC Pregnancy Childbirth. 2019;19(1):322

\section{Publisher's Note}

Springer Nature remains neutral with regard to jurisdictional claims in published maps and institutional affiliations.

Ready to submit your research? Choose BMC and benefit from

- fast, convenient online submission

- thorough peer review by experienced researchers in your field

- rapid publication on acceptance

- support for research data, including large and complex data types

- gold Open Access which fosters wider collaboration and increased citations

- maximum visibility for your research: over $100 \mathrm{M}$ website views per year

At $\mathrm{BMC}$, research is always in progress.

Learn more biomedcentral.com/submission 